\title{
Architecture
}

\section{INBETWEEN HETEROTOPIA AND SIMULACRUM: VERNACULAR LANGUAGE OF COURTYARDS IN BANGLADESH'S ARCHITECTURE}

\author{
Ar. Sayed Ahmed \\ lecturer, Department of architecture, Bangladesh University \\ 15/1, Iqbal Road, Mohammadpur, Dhaka - 1207, Bangladesh \\ E-mail: ar.sayedahmed@gmail.com
}

\begin{abstract}
Introduction: The courtyard was perceived by generations just like a religious act in Bengal delta. Even the community cohesion of the courtyard space was repeated and maintained in the township context, which neither belongs to agricultural nor working class but rather to educated elites with western zest. How has this unique feature been evolving and why is the appeal still the same today? Is the courtyard's permeability just the 'in-between space' or was it derived from the aspiration of philosophical legacy? Methods: The study uses a twofold method derived from solid-void relationships. Firstly, eastern and western philosophical discourses were compared, and the extensive literature review is presented. Secondly, historical evidence and logics behind the courtyard's position from micro to macro scale, from household to city formation is presented and analyzed in the philosophical context. Results and discussion: From a very complex lattice and layers related to architectural philosophy, two important figures of western world, Baudrillard and Foucault's ideas proved crucial to comprehend how an image of the courtyard remained constant and how it is empowered as a core space from the socio-cultural and functional views. The result affiliated western objectives and eastern subjectivity.
\end{abstract}

\section{Keywords}

Courtyard, Bengal architecture, conception of space, heterotopia and simulacrum.

\section{Introduction}

Chronological history of society depicts the changing pattern of human settlements. Embedded with commonplace behavior, such architecture created a language by combining a true approach and conceptualization. Better observation is always proportionate to better imagination. It is something related to observation of the surrounding watery landscape. Altogether, vernacular architecture is the best experiential essence of livelihood and psychological meanings. The vernacular courtyard germinated operative spaces to rationalize its presence. Solidity of any form built around or apart is called 'served spaces'. Although a lot of differences are evident in every single example of vernacularism, the architecture of Bengal never forgot its homesickness to this basic element, a deliberately 'left over' void which is full of activities, its mode undefined.

\section{Literature Review}

\section{The three windows of Bengal}

It's difficult to say what the fundamental style of Bengal architecture is, as the nation like the Bangladesh has been under several foreign influences for centuries. For nearly a millennium of Middle Eastern invasion, the architecture absorbed all the foreign elements according to its own zest. Bangladesh has only three remaining windows to retrospect and look through the architectonic past. Firstly, it is important to mention the archaeology of Buddhist Viharas, which are actually massive monasterybased Buddhist universities in some archaeological sites along with the oblong direction of holy Ganges. Those are river port-like settlements. Some examples of these archaeological sites are Paharpur, Mainamati and Mahastangarh built with Bengal's unique terracotta art, special brick modules and Buddhist architectural style, dating from the $7^{\text {th }}$ to $13^{\text {th }}$ centuries (Bandyopadhyay, 2016). The premises were unique and influential in the whole South-East Asia, and the temple architecture in the Indo-China belt wanted to achieve such artistic state. 'Mahasthangarh' means 'the most magnificent place on earth' (Ahmed, 2013).

Secondly, it includes medieval small-scale mosques and temple architecture of its own style. In fact, medieval Sultanate architecture was the first attempt to search for the own architectural style (Ahmed, 2006). However, the burning question comes: why could the traditional temples of India and Persian mosques not continue their rectitude pride in Bengal? The reason is that they either had a small scale or got fused with vernacular elements which were erected with local plasticity, Bengal bricks to resist this 
country's most venerable challenge - the climate. To be exact, floods and a 6-months monsoon season were the challenges.

And lastly, vernacular architecture in different rural contexts and topographies, which evolved to tackle all the climatic issues through a series of successful inventions over time, was an important component. Amongst all these, vernacular architecture is the most important for better understanding of this study, as it aims to be a fundamental one. The answer is always echoed from subaltern population with its responsive architecture. The construction technique and durability, planning and its inherent qualities to achieve the climatic responsiveness or cost effectiveness were proved well-judged to ensure comfort in this hot dry region. These were the solutions to confront the natural problems which evolved a common architectural soul, the courtyard. Again, the adages and maxims of the estimated time period that ranges from the $4^{\text {th }}$ to $12^{\text {th }}$ centuries were formulated by an ancient wise lady of Bengal, folk poet Khona, and are still popular among the agricultural societies of villages related to planning and proved contextual for this esteem (Ahmed and Ahmed, 2015). This again belongs to folklore culture which is synonymous to vernacularism, somewhat like architecture without an architect.

From the above discussions we can assume that architecture starts from nature, especially from the scale of a branched tree and the entrance approach of any natural cave. Nature was the first and foremost motivation of any architectural composition and fitted especially well in vernacular architecture, in its courtyards. When somebody is born, gets married or dies, the courtyard serves an assembly but of course the modes are of different environments. It's beyond any kind of definition and is multi-functional without the need of any built structures, it's a container but also its character is contained. Why does our traditional courtyard seem empty but full of activities? Community cohesion of courtyard spaces from Neolithic villages is still contextual for well-desired happiness. The stories of courtyards even brought life experiences from villages and transformed them into vibrant cozy spaces at every city dwelling. The traditional courtyard seems empty but full of activities: birth to death, marriage to quarrel. Stories of courtyards are a legacy: grandparents, as well as senior citizens, shape the realm of children there. This is also a legacy for education if somebody wants to practice craft or agriculture. Here masters meet their apprentices. Courts are educative by all means. Let us discuss the architectural order and its spatial quality of this feature.

\section{The courtyard: the architecture of voids}

In Bangladeshi villages, life has always been active through agro-based society. Architecture of this soil is essentially an expression of subaltern societies and constitutes the psychic of the amateur masons. Such agricultural society had plagiaristic approach in its lifestyle from dust and mud, which influenced its creation profoundly with self-effacing thatched huts made of mud, wood, hay, straw, clay, bamboo, etc. Vernacular architecture got remarkable variations, but a closer observation will reveal every individual hut gain its own inimitability. These houses have similar morphological characteristics as all the household works are arranged around an introverted central courtyard acting like the nucleolus of the house (Muktadir and Hasan, 1985). The length and width of the courtyard vary from minimum 10 feet to maximum 30 feet. A tree or a number of trees are one of the key parts of the courtyard's scale.
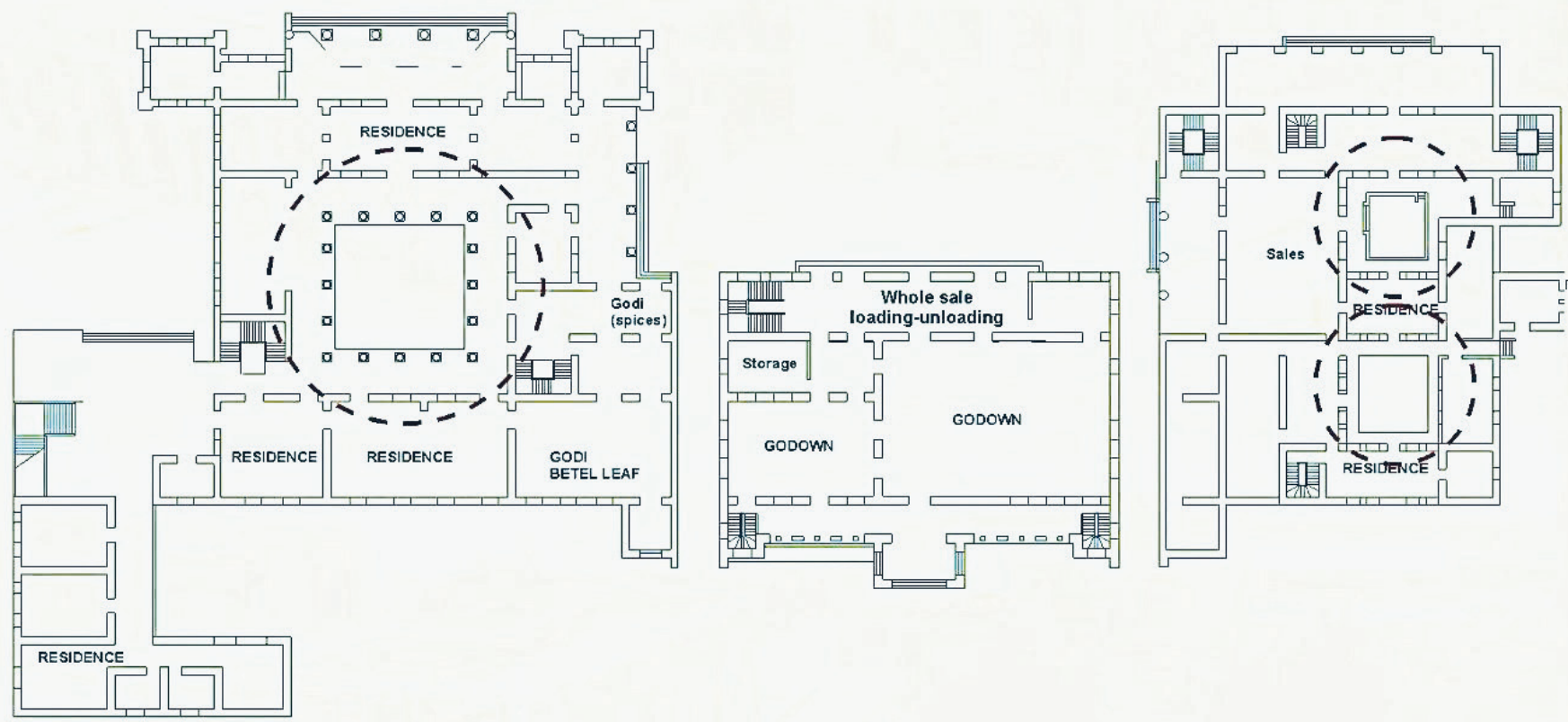

Figure 1: The traditional pattern of vernacular architecture, a cluster around a courtyard echoed in colonial architecture of Ruplal house, collected from bachelor thesis of Martuj Rasel, Bangladesh University, 07.02.2014 
Yet, new elements of daily experience, such as knowledge, value and behavior, are always allowed to be absorbed into certain attitudes that are deep within the psyche of inhabitants' collective consciousness and condition (Haque, 2009). Every detail comes from practical understanding; every planning decision comes from the user's need where the local wisdom lies.

Such indigenous architecture has a clear relationship to its collective religious behavior and norms. In fact, subaltern dwellings respect the lattice of intensity and contextually. Human behavior generated diverse forms in its spatial representation, which eventually converted indigenous public spaces like courtyards into an effective workstation (Nilufer, 2004). A homestead is an amalgamation of indoor and outdoor spaces (Kabir and Mallik, 2009). The scale of the semi-outdoor space needs to be very intimate and humane. A simple wall then gives an enclosure to the complex, gives the sense of privacy, accommodates the ancillary facilities and overall, defines an introvert sense of belongingness. Everything is possible for 'an open to sky' hollow in the planning, which can be used regardless of weather. The courtyards always accommodate the socio-cultural preferences of a particular community; even if they lose their function. Such image of a village also reflects the early settlement patterns of old Dhaka, sometimes referred to as 'township'. The openness of courtyards is also a good example of semi-public functions that successfully adapted to the congested urban fabric (Khan, 2006). Interestingly, it was possible to shift a whole house with boats with the benefit of water connectivity through canals even 100 years ago. They were erected around a desired court, in the newly owned land of the town context, a new place in a usual search for happiness.

As such architectural order has been developed from the daily needs of local people, the built environment and the pattern of spaces are the products of the daily interaction of dwellers with their neighbors. The degree of privacy is provided by the planning layout, so that it can maintain the socio-cultural balance of these rural communities. As the courtyard is surrounded by the enclosing wall, it also has privacy, so both men and women can use it simultaneously. It looks as an absolutely complete and matured plan with thoughtful insight. The most amazing feature is the rationality of space and clarity of the planning organization. The plans usually represent a square, where the focal organization is the courtyard. As the spaces are placed so carefully, it might seem that it is a craft where everything is perfect according to its needs (Hossain and Alam, 2012).

\section{Conceptualization from Metaphysics}

Conceptualizations of places differ among different people, and their meanings are not manifested in material space. Appreciating this concept is a vital precursor for understanding any vernacular settlement in the world. The specific meanings and conceptions of places can shape the core of any culture with a profound impact upon their daily behavior: both being and becoming (Rapoport,
1975) together with agro-artisan practices. The vernacular settlement can thus be seen as a system of spaces and places that are attuned to provide the settings and opportunities to sustain peaceful and fulfilled daily lives as much as for seeking and attaining a higher state of being in the future lives (Dayaratne, 2010).

From this point of view it can be seen that craftsmen and peasants in traditional Bangladeshi villages have very similar world views, indeed bound by an undeniable inter-dependency.

Regional philosophy is also common for every particular community with the same imposed cultural context. What does a court mean for the way of life? Let some philosophy get involved. According to Buddha; space is beyond any definition:

'This world is nil.'

Or

'To abandon is to get fulfillment.'

If the folk philosophy is not involved, then we might not do the right thing to judge the spirit of this land. Similarly, Lalon (1774-1890), the soul of this soil, said:

$$
\text { ‘খাঁচার ভতির অচনি পাখণ ক৮মনট আস৮ যায়’ }
$$

It means: As a bird, a soul comes in and gets out of the 'cage' represented by a human body or structure (Shorkar, 1982).

In fact, it is necessary to introduce Lalon properly for this study. He was a mystic saint, songwriter, social reformer and thinker; the best folk poet, lord of the Bauls that Bengal has ever got. He became an icon of religious tolerance, his songs evoked many of the later poetic mastermind's philosophical thoughts including the first Asian Nobel Prize winner Rabindranath Tagore (Haque, 2017).

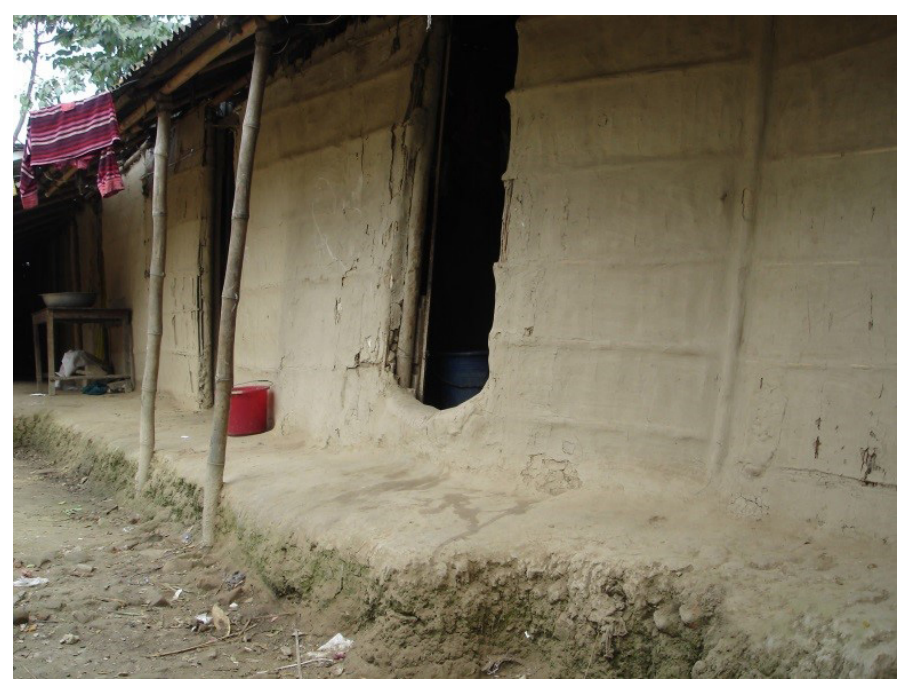

Figure 2: A 'Gosshaghar' for an unmarried lady in Sunamganj. Source: Author 2012-01-07 
It is estimated that he had composed nearly 10,000 songs out of which it was possible to track down only 2,000 to 3,000 ; not in the written form but in the hearts of his numerous followers who could neither read nor write. His songs are also recognized as intangible UNESO heritage.

In architecture, light, water and wind can be represented as an idea of 'happiness' (Ahmed, 2017) and the architecture incorporating all these ideas could be thought of like a cage. A perforation in architecture may be one kind of expression for such freedom. Master mind Louis Kahn utilized this idea when he was bestowed with the duty to construct the Parliament building of Bangladesh, probably the most magnificent parliamentary building of the world and his architectural masterpiece (Curtis, 2012). His well-established theory of 'served and service' areas, their realization for people's needs and how to cater them from a court was inspirational for this master mind. Again, Lalon's thoughts and the first modern French philosopher Rene Descartes's 'Intuition' are the same in this regard, and we see the culmination of realism depicting a human in the center:

\section{"I think, therefore I exist".}

Later, Freudian idea indicated that subconsciousness of human mind was freedom. (Perforation). However, the challenge is that only architects need to create the reality, while all artists got the rights to create the false or illusions.

Let us now go back to the period when the human civilization invented fire and its associated spaces from where this study started its discussion. It could be identifiable now from all other cultures, private and public, family and social, leisure and work, that such classification indicates a hidden presence of sacred spaces. Primitive society is the best example of crisis and its space according to Michel Foucault is called heterotopia. Spaces of heterotopia give the essence of 'another space' within a space (Foucault, 1997) and are really powerful. Human mind is in elsewhere if it comes to contact with these spaces. Some opposite heterotopias are temporal and connected with time. They are accessible if arranged for any public event, but responsive only in the particular season. Heterotopias develop a system of opening and closing as they are not freely accessible. The function plays the vital role to create illusion, but also ensures social interactions (Foucault, 1984). For example, trade fair ground in the winter landscape of Hoar areas and the 'Gossha ghar' or room of anger where an unmarried girl is given a peer to wait for her marriage after the next monsoon.

As an important western concept-binder, this study wants to introduce Mitchell Foucault. He considers an axiom that states that 'Liberty is practice' and concludes that architecture cannot be fundamentally oppressive either. It is also agreeable to some extent that 'the architect has no control.' Again, a perfectly elaborated set of lines that any architect creates in their drawings will not materialize with the same level of perfection than he has imagined initially (Ahmed, 2016). A simple example of an architectural element could be the door, which is a device to any functional allowance, from the impenetrable state of being closed to the porous state of being open for entry (Foucault, 1982). However, courtyards are open, but again one needs to seek permission there, with scaling or narrowing the pave or by vegetation, which creates an environment to mound one's psychology. It could be referred to as a planning diagram, as every human being is an architect from their inert. Foucault reads this architectural diagram through a two-dimensional form of representation, which expresses various forces created by its lines. If the courtyard is the meeting point of such lines, it does not show the influence, rather defines the edges. Again it avoids all those influences, as it wants to remain independent from any kind of alignment, rather invisible diagonal forces are predominant for the connecting purpose. This is the basic idea of Foucault's interest, known as cartography. It is the activity that considers a given situation within the reality and elaborates diagrammatic representation.

\section{'It is a machine that is almost blind and mute, even though it makes others see and speak.'}

Moreover, Foucault focused his interest on human science, which is closely connected with the society, psychology, sociology, economics, linguistics and medicine (Foucault, 1979). Above all, his 'so called' power of spaces is very contextual for the courtyard study. It is the court of law for judgment from the very early period of human's social settlements. It is also the court of one's social status: whether you are from agricultural or craft-based society, it always tends to reflect its owner's economic character. For linguistics, the gathering of Bauls with a central fireplace could be the best example. The penetration of the sacred herb like Tulsi (Ocimum tenuiflorum) in a Hindu courtyard is an example of herbal medicine. The courtyard is the symbol of all basic needs as well as the fundamental space for every aspect in exercising the power.

And, most importantly, courtyards are also a flexible example of 'Panopticon' (Foucault, 1995). They are visible and audible from one's known realm and center of a simple controlled indigenous and initial society, but, of course, a successful example for the degree of observation and freedom. It is not a prison, but is the society behind courtyards with religious rituals and social norms not an invisible prison? What one cannot do in the courtyard cannot be done in public places either. The imperceptible 'prison' starts from educative courtyards.

Even to assume the sun clock, the courtyard tells the reality about the time and rural people's experience of time, and this knowledge is well adjusted there. This practice led ancient people to be caught up in time. And this being 'caught up' is always poetic. Open-to-sky spaces are thus divine from the view point of the architect Charles Correa and one can relate its spirit with spirituality. According to Heidegger, humans, thus, are dwelling poetically (El-Bizri, 2015). The courtyard is the rhythm of that poetry. 


\section{The anti-courtyard}

Does this courtyard only convey the core idea of all our built forms? It may not always be true. In another context, 'Mer' in a haphazard but intimate scale from the civic perspective of old Dhaka is also an exemplification of the 'beyond the ownership' concept. It is a civic practice where an elevated spacious veranda without any fencing is kept for serving the purpose for public resting and childish activity in front of a roadside private home. It is prominent that the architecture of freedom and sharing in an intimate cluster was never omitted. This vernacularism got its root in water, not by means of defending, but to adapt to a smaller floating scale. Let's discuss one and the only available example in this region.

In the country with more than its fair share of cultural diversity, the Bede people are not only distinctive in their traditional lifestyle but also in their religious, social and cultural patterns. The estimated 1 million river gypsies or nomads of Bengal, the name derived from the Hindu cast Baidda, means doctors or people of profound knowledge in medicine. They are descendants of 'Montong' tribe of Myanmar. They are highly regarded in our folk culture,

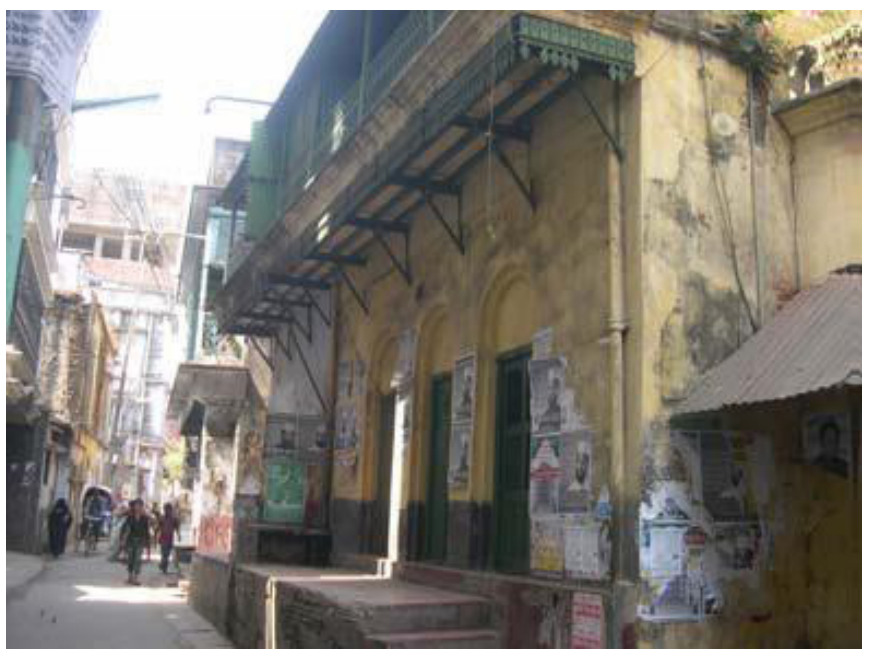

Figure 3: Mer, full of joys and activities regardless of ownership. The photograph from the PhD thesis of Iftekhar Ahmed, Honkong, Street house interface: Some basic elements of Old Dhaka Urbanism. Page 143 (2012)-01

as they charmed snakes, performed magic, trained monkeys, and practiced traditional medicine and spiritual healing (Dalton, 1978). The Bede people used to live in boats, they travelled in groups from one village to another for 10 months every year, stopped in almost 90 villages on their way and seldom stayed for more than 3-4 days in one spot. They rested a couple of winter months, settled for rest, marriage, and other social functions, when all the rivers had already dried out. These are semi-tubular shaped tents, covered with bamboo fences. The Bede

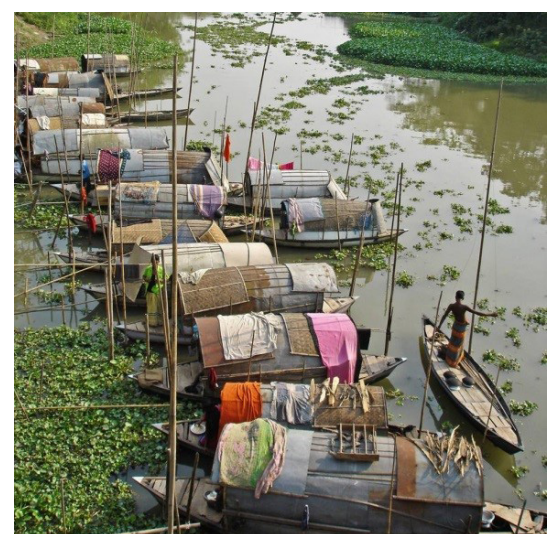

Figure 4: Bede's boat dwelling or series of courtyards.

Available at (https://cafedissensus.files.wordpress. com/2016/07/2-bede.jpg?w=217) accessed on 11. 07. 2017

Courtesy: Carmen Brandt, Café Dissensus, 2016-07-19 people's distinctive socio-cultural pattern at their boat's hollow follows the similar sequence of courts, but they float. The floating courts are heterogeneity that helps to continue their dreams.

There are 65 prominent areas in Bangladesh where Bedes come for yearly gathering. Since Bedes have to live either in small boats or tents, the average per capita living space enjoyed by them is much less than city's slum people who suit in a 10 square feet accommodation (Maksud, 2006).

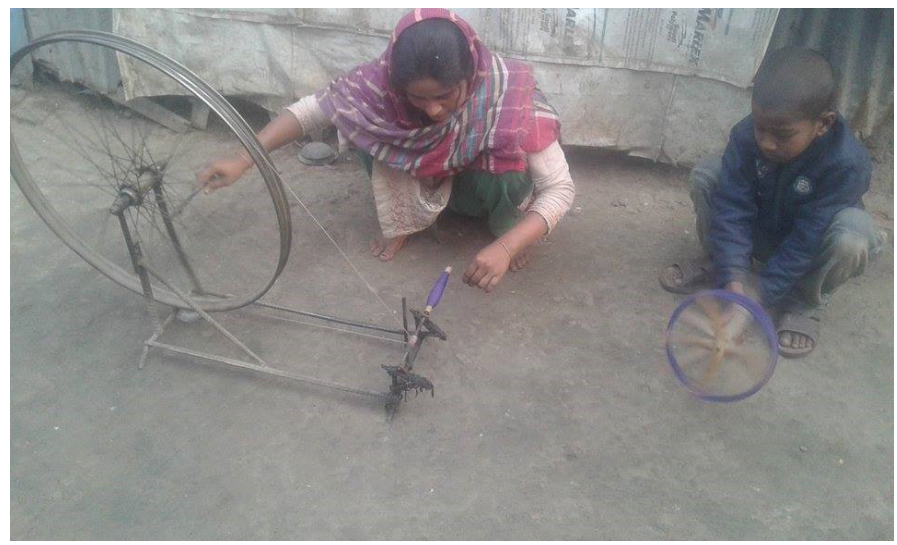

Figure 5: An educative courtyard of weavers in Tarabo Jamdani village, Narayanganj. Source: Author 2017-03-26 


\section{Finding and Analysis}

After the careful literature review, this study shapes the findings according to Baudrillard's vision. As an opponent of Foucault's post structuralism, Baudrillard is his antagonist, a worshiper of hyper reality. His hyperrealism depends on the 'image making', which he successfully called simulacrum. This may include perception, religious imagery, natural phenomena, creative engagement and spiritual rendezvous of our experienced environment along with psychology. According to Baudrillard's idea, simulation is an active process of replacement of the real. Simulation threatens the difference between the 'true' and the 'false'; the 'real' and the 'imaginary'. In its advance stage it turns into hyper reality, which is in fact the generation of symbols of the real without origin in reality. Simulation refers to a process in motion, whereas simulacrum (plural simulacra) refers to a more static image.

Now, there are 4 orders of such 'image making' according to Baudrillard:

1. Faithful: The image reflects a profound reality. This is always present in traditional and social hierarchy. It is a direct copy of reality. For example, classical paintings and sculptures in Europe.

2. Perversion: Masks and perverts of any profound reality. This is the aesthetical tool to pervert the basic spatial reality.

3. Pretense: the absence of profound reality. Disneyland is an example.

4. Pure: Own pure simulacrum. Substituting signs of the real for the real itself. Here, representation comes from simulation but later it becomes a sign of simulacrum. It is the ultimate matrix, the known world is an illusion now.

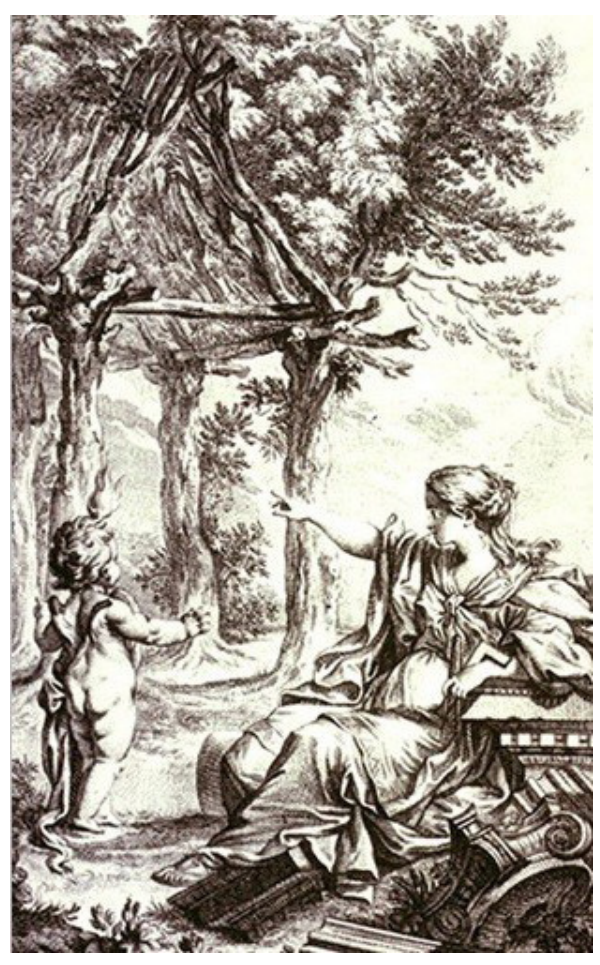

Figure 6: Marc-Antoine-Laugier: the primitive hut, 1753
Buadrillard wanted to focus on the symbolic acts of image making. In his four Objective Value Systems mentioned above, the first three values are direct simulations of nature.

At the Faithful stage, architecture depends on the architect's imagination and observation, proportionate to each other. For example, cave architecture in Lomus Rishi cave in Bihar dated from the 3rd century BC is the direct representation of primitive caves. Marc-Antoine L'Augier's painting in his book 'Essay on architecture' from 1755 has already shown us that architecture starts from nature. Vernacular architecture around the world tends to imitate this reflection sill.

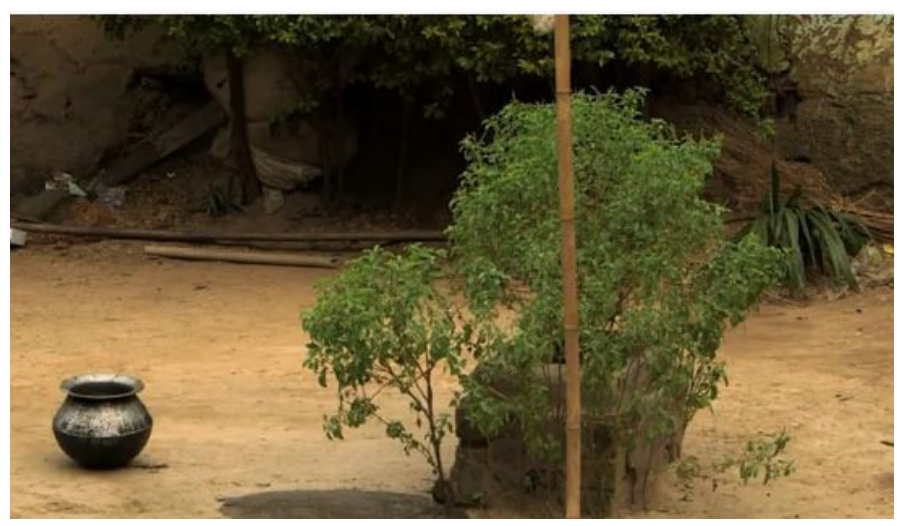

Figure 7: Hindu courtyard's identity is Tulsi tree

Perversion is the second stage of simulation. He puts 'symbolic value' in the third place where he describes any object in relation to another subject. A higher idea takes a real object as a vehicle and also symbolizes the reality. The second stage has a lot of examples. For example, fire representing spirit in Baul's homestead, an icon like Tulsi tree in Hindu court are the classical examples of simulacrum of this stage. Once Loius I Kahn asked the brick what it wanted to be, and the answer was an arch. It was in his mind, in his vision, the brick was just a medium to express it. Again, the modernist period in architecture regarded ornamentation as crime, it shows how basic reality can be absent and presented by simple, basic and architectonic shapes and platonic solids or volumes. Again, it has some 'sign value' which indicates the system of objects. For instance, the social status has always been perfectly represented in Bengal's courtyards. Whether they belong to craftsmen or aristocrats, the activity flourishes its space character. In fact this is the border line that all architects deal with; this stage is the limit of the image making and representation option.

The third stage is also present in the courtyard, but how? Different sorts of amusement installations and our imagination convert us into desired superheroes and we have different roles playing with the peers - everyone can make any courtyard into a mini Disneyland. It could also be educative.

Architecture is a supreme medium of visual culture, no doubt. It naturally reflects any individual's perception of reality; even the creator (architect) is a part of it. 
'Singularity' can be considered as an object and there is nothing homogeneous or global. Regardless of the region, cultural background, time and people, the courtyard is universal, but again it is local. The courtyard contains different simulations, which reflect topography, sociocultural and even political contexts. However, it is a real multifunctional void which is not definable. It fulfills the first three stages of simulacrum as this study finds.
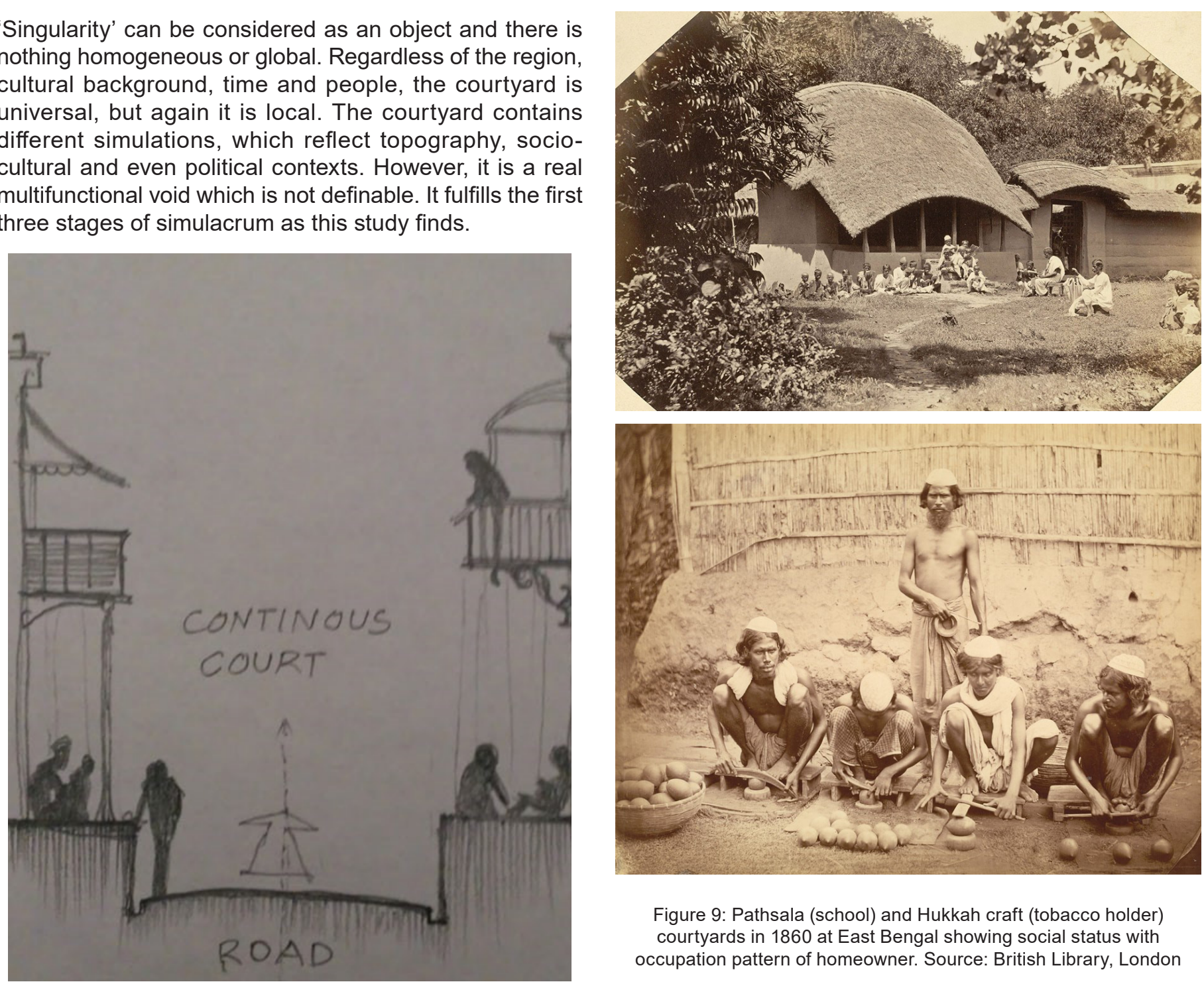

Figure 9: Pathsala (school) and Hukkah craft (tobacco holder) courtyards in 1860 at East Bengal showing social status with occupation pattern of homeowner. Source: British Library, London

Figure 8: Chat of Roak and Streetscape created the 'sense of continuous courtyard' in old Dhaka

Just like 'hope' or 'dream' in the theory of Foucault's heterotopia, a boat of Bede community could be seen as an exception but not aloof from courtyard's uniformity. Similarly, Mer conception of old Dhaka creates courtyard like a sense from a streetscape if offered on both sides of a narrow road. Such street could be a continuous courtyard. The landscape is much more powerful than architecture, and the courtyard is the reminding character of that landscape, where architecture should return to a form of archaeology. In modern and contemporary architectural practices, prominent architects of Bangladesh have never overlooked its presence in their works but rather promoted courtyards in the design style and site context.

\section{Conclusion}

Western and Eastern philosophies might come to the same point to define what the meaning of nothingness of any undefined space is, which is actually this study's core conceptualization. Mystic eastern philosophies like to nullify and void in the built form and circulation around a

well established by their functional organization Buddhist architecture. For subaltern people this was their court, simply a void of nil but responsive to their basic needs, as Foucault identified. This is as ancient as the first spark of fire. Heterotopia exists, but it is merely identifiable from the primitive concepts and changes of seasons over the given topography, it plays the vital role to feel the poetic essences of phenomenology. There is a passive control in nature, and humans also do know how to educate themselves, which starts from the most primitive institution like the family, while classroom is a social invisible prison of educative courts. Foolish architects always trap themselves into an 'optical prison' where the architecture does create or shape architects, but architects cannot create architecture.

In fact, cozy spaces from the very early childhood of a person are important for their identical spatial quality. Terraces, pergolas, verandas, open-to-sky courts, semioutdoor spaces are such sort of spaces that have a more meaningful origination in vernacular architecture than any designed one. Biennial characters have great impact over those micro-climate spaces both in lateral and frontal elevations. Structural systems and fenestrations, 
of course, for the design consideration of a particular climate shaped the housing with those beautiful and happy 'trivial' spaces. Neolithic villages differed from region to region as the topography differs. It reveals the issue of high population density in Bangladesh. Flourishing of such villages since $2500 \mathrm{BC}$ was the key reason along with the natural water networking. Thus, the community cohesion was still maintained in the organic town planning with water connectivity. And the most evolutionary invention of humans, the fire, was discussed at the very beginning of this study as a witness of the courtyard's unforeseen role in different cultures. To recapitulate, it is distinct now that our 'courtyard spaces' are aspirations based on our agricultural legacy considering something 'in-between' in overall space. Clustered 'in-between' spaces of such vernacular architecture altogether created ancient villages. And again, connecting all villages along waterways shaped the ancient civilizations in this subcontinent and in other parts of the tropics where it was possible for humans to be well suited to the tropical belt of earth. Such 'happy courtyard series' resulted in villages. These villages were the first to be evolved for the succession of ancient human civilizations. 


\section{References}

Ahmed, S., Ahmed, F. (2015). The Maxims of Khona: A Contextual Study of Sustainability over Vernacular Architectural Practice of Bangladesh. Journal of Modern Science and Technology, 3 (1), pp.1-19.

Ahmed, Abu. Sayeed. (2006). Mosque architecture of Bangladesh. UNESCO. Bangladesh: Dhaka, 207 p.

Ahmed, S. (2013). An imagination of Bikrampur Buddhist Vihara from the foot-print of Atish Dipankar's travel. American Journal of Engineering Research, 2 (12), pp. 276-295.

Ahmed, S. (2016). Philosophy of Architecture; Architecture as Philosophy - the potentialities in accordance to the critical sermon. International Journal of Architecture, Engineering and Construction, 5 (2), pp. 83-97.

Ahmed, S. (2017). Vernacularism in the vibrant courtyard space of Bangladesh: The architectural art of happiness. Arcasia forum journal. Jaipur, India. p. 121.

Bandyopadhyay, S. (2016). Background and Influence of Bengal Terracotta Temple Architecture (16th -19th century AD) on Arts and Crafts of Bengal. The International Journal of Humanities \& Social Studies, 4 (4), pp. 65-75.

Curtis, W. (2012). Louis Kahn: The Space of Ideas. The architectural review. Available at: https://www.architectural-review.com/ louis-kahn-the-space-of-ideas/8637503.article (accessed on: 15.04.2019).

Dalton, E.T. (1978). Tribal History of Eastern India. New Delhi: Cosmo Publications. 339 p.

Dayaratne, R. (2010). Conceptualisations of Place in the Vernacular Rural Settlements of Sri Lanka. South Asia Journal of South Asian Studies, 33 (3), pp. 381-398.

El-Bizri, N. (2015). On Dwelling Heideggerian Allusions to Architectural Phenomenolog. Studia universitatis babeş-bolyai. Philosophia, 60 (1), pp. 5-29.

Foucault, M. (1979). Power/Knowledge: Selected Interviews and Other Writings 1972-1977, New York: Pantheon Books, 270 p. Foucault, M. (1982). Space, Power, and Knowledge. Interview with P. Rabinow. Skyline.

Foucault, M. (1984). Of Other Spaces: Utopias and Heterotopias. Architecture /Mouvement/ Continuité, October. (Des Espace Autres, March 1967 Translated from the French by Jay Miskowiec).

Foucault, M. (1997). Of Other Spaces: Utopias and Heterotopias. Rethinking Architecture: A Reader in Cultural Theory. New York: Routledge. pp. 330-336.

Foucault, M. (1995). Discipline and Punish: The Birth of Prison. New York: Vintage Books, 333 p.

Haque, E. (2017) Fakir Lalon Shah: A prominent Bengali philosopher, mystic and an icon of Bengali Literature. International Journal For Excogitation Education and Research, 1 (2), p. 43

Haque, K.H. (2009). Dhaka and the contestation over the public space. City journal, 13 (1), pp. 129-136. DOI: $10.1080 / 13604810902726343$.

Hossain, M.S., Alam, S. (2012). Learning from Rural Vernacular: Appreciation and Need for Retrofitting, International seminar proceedings of architecture: education, practice and research, Dhaka, pp. 368-383

Kabir, K.H., Mallik, F.H., (2009). Dynamic Vernacular - Outdoor spaces in the homesteads of the ultra-poor. In: 3rd International Seminar on Vernacular Settlement, Indonesia.

Khan, I.A. (2006). The Rural Bangladeshi Courtyard. BRAC University Journal, 3 (1), pp. 9-15.

Maksud, A.K.M. (2006). Participatory Action Research for Human Development of Nomadic Bede Community. Grambangla Unnayan Committee and Research Initiatives journal of Bangladesh, 5 (2), pp 54-70.

Muktadir, M.A., Hasan, D.M. (1985). Traditional house Form in Rural Bangladesh: A case study for Regionalism in Architecture. In Regionalism in Architecture, pp. 81-86.

Nilufer, F. (2004). Hidden Morphological Order in an Organic City. Protibesh, 10, pp. 33-40.

Rapoport, A. (1975) Australian Aborigines and Definitions of Place. In P. Oliver (ed.), Shelter, Sign and Symbol. London: Barrie and Jenkins, pp. 38-51.

Shorkar, S.A. (1982). Lalon Shaher Moromi Dorshon, (Mystic philosophy of Lalon). Dhaka: Bangla Academy. 